\title{
Renal Functional Status of Asphyxiated Babies \& its Correlation with Apgar Score
}

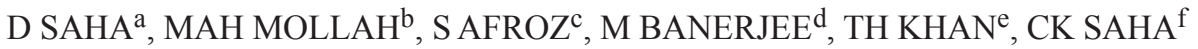

\begin{abstract}
Summary:
Introduction: Kidney is the $2^{\text {nd }}$ commonest affected organ as a consequence of asphyxia ${ }^{1}$. Most attention is given to prevent CNS damage and neurological sequel but hypoxic renal insult not only influences neonatal morbidity \& mortality but may give rise to CKD. to assess the renal functional status of asphyxiated babies.
\end{abstract}

Material \& Methods: This cross sectional study was conducted in the Department of Neonatology \& Department of Gynecology and Obstetrics, Dhaka Medical College Hospital during January 2012 to January 2013. A total of 150 inborn, term asphyxiated neonates with $e$ " $2.5 \mathrm{~kg}$ who had history of delayed or no cry with Apgar score $<7$ at 5 minutes were enrolled. Then, the cases were grouped into mild (AS: 6-7), moderate (AS: 4-5) and severe asphyxia (AS: 0-3) based on Apgar score. Forty eight neonates were excluded according to exclusion criteria. Finally, the renal functions were assessed among 102 neonates by measuring urine output 8 hourly and estimated creatinine clearance (eCCL) on the 3rd day of life using Schwartz formula $($ eCCl=Height $(\mathrm{cm}) \times .37 /$ S.creatinine $)$. Neonates with impaired renal function were further classified as stage-I (risk), II (injury), III (failure) using pRIFLE criteria. Data were analyzed by Chi-square \& Pearson correlation coefficient test to find out correlation between Apgar scores and renal functional status.

\section{Introduction:}

Perinatal asphyxia causes damage to almost every tissue and organ of the body, particularly CNS followed by renal, adrenal, cardiovascular, GIT and respiratory

a. Dr. Dipa Saha, Assistant Professor, Department of Pediatrics, Bashundhara Addin Medical College Hospital, Keranigonj, Dhaka

b. Prof. Md. Abid Hossain Mollah, Professor, Department of Neonatology, Dhaka Medical College Hospital

c. Dr. Shireen Afroz, Associate professor, Department of Nephrology, BICH \& Dhaka shishu Hospital, Dhaka

d. Prof. Manisha Banerjee, Professor, Department of Neonatology, Dhaka Medical College Hospital

e. Dr. Tofazzal H khan, Associate Professor, Department of Neonatology, Dhaka Medical College Hospital

f. Dr. Chinmoy Sumar Saha, Assistant Professor, Department of medicine, Comilla Medical College Hospital

Address of Correspondence: Dr. Dipa Saha, Assistant Professor, Department of Pediatrics, Bashundhara Addin Medical College Hospital, Keranigonj, Dhaka, Mobile: 01717337891, Email: dipasaha182@gmail.com

Received: 11 Nov. 2015

Accepted: 13 April 2016
Results: Of the 102 cases studied, majority $48 \%$ were in moderate, $30.4 \%$ in mild and $21.6 \%$ in severely asphyxiated group. In the mild asphyxiated group $58.06 \%$ had normal renal function. However, the remaining cases $29.03 \%$ \& $12.90 \%$ had stage I, stage II renal injury respectively and had no renal failure. In Moderately asphyxiated group, $26.53 \%$ had normal renal function \& the remaining $32.65 \%$, $34.69 \%, 6.1 \%$ had stage I, II, III renal injury respectively. None of the severely asphyxiated babies had normal renal function. However they had impaired renal function ranging from Stage I (27.27\%), stage II (27.27\%) \& stage III (40.90\%).Variable proportion of kidney injuries were noted among the asphyxiated neonates. The lower the Apgar score, the more severe the injuries and association between stages of kidney injuries and Apgar score was observed statistically significant $(p<0.001)$. The renal functional status (eCCL) was also found positively correlated with low Apgar score $(r=0.6, p<0.002)$.

Conclusion: Variable functional impairment of kidneys was found among the asphyxiated neonates and the severity of impairment significantly correlated with low Apgar score.

Key wards: Perinatal asphyxia, apgar score, Acute kidney injury.

(J Bangladesh Coll Phys Surg 2017; 35: 128-132)

system ${ }^{2}$. As kidneys are very sensitive to oxygen deprivation, renal insufficiency may occur promptly even within 24 hours of asphyxia ${ }^{3}$.

Serum creatinine as a marker of GFR/renal function in neonate is doubtful, because it remains raised and variable during the $1^{\text {st }}$ month of life ${ }^{4}$. N-Acetyl glucosamine and ${ }^{2} 2$ micro globulin are good marker for assessment of renal function ${ }^{5}$. But in Bangladesh these investigations are not widely available even in tertiary level. In 2004, the Acute Dialysis Quality Initiative (ADQI) proposed an acute kidney injury (AKI) classification system called "Risk, Injury, Failure, Loss, End-Stage Kidney Disease (RIFLE)" criteria to promote a consistent and consensus AKI definition ${ }^{6}$. Subsequently RIFLE criteria were modified for children and RIFLE changed to pediatric RIFLE criteria or $\mathrm{pRIFLE}^{7}$. This classification system is based on calculation of eCCL (using s. creatinine level of patient) and 24 hours urine output. Then acute kidney injuries 
are classified as stage 1(risk), stage2 (injury) and, stage 3 (failure) by using any one of the criteria, eCCL or urine output criteria. Risk means eCCL decreased by $25 \%$ and urine output $<0.5 \mathrm{ml} / \mathrm{kg} / \mathrm{hr}$ for 8 hours, injury means eCCL decreased by $50 \%$ and urine output $<0.5 \mathrm{ml} /$ $\mathrm{kg} / \mathrm{hr}$ for 16 hours and failure means eCCL decreased by $75 \%$ and urine output $<0.3 \mathrm{ml} / \mathrm{kg} / \mathrm{hr}$ for 24 hours or anuric for 12 hours $^{8}$. So in this study a correlation was searched between available renal function marker and perinatal asphyxia, so that renal impairment can be predicted early in asphyxiated neonates. Therefore, high index of suspicion, prompt recognition and thorough understanding of impaired renal function are necessary to optimize management.

\section{Materials and method:}

This Cross sectional study was carried out in the Department of Neonatology and Department of Gynecology and Obstetrics, Dhaka Medical College Hospital from January 2012 to January 2013. A total of 150 inborn asphyxiated neonates who had history of delayed or no cry with Apgar score (AS) of $<7$ at 5 minutes, weight e" $2.5 \mathrm{~kg}$, gestational age e" 37 completed weeks were selected by purposive sampling. A written informed consent was taken from parents before enrollment. Relevant perinatal history and examination findings were recorded in a structured questionnaire. Then, the cases were thoroughly assessed and managed following the resuscitation protocol with close monitoring. The respiratory status was assessed by monitoring RR, chest expansion, air entry \& $\mathrm{O}_{2}$ saturation, the CVS status by monitoring pulse volume, HR, color, CRT, Pulse oximetry, \& temperature. Neurologic status was assessed by Sarnat \& Sarnat staging 9 for HIE every 12 hourly. Daily weight recordings were taken on an electronic scale. 8hourly urine output measurements were done by applying plastic urine collection bag or by weighing the wet diaper. On the basis of Apgar score at 5 minutes which was written on referral note, asphyxiated babies were further grouped into mild (6-7), moderate (4-5), severe (0-3) asphyxia. Forty eight neonates were excluded due to Sepsis (13), Jaundice (9), DORB (7), congenital renal anomaly (1) and death before $3^{\text {rd }}$ day (18). Finally renal functional status was assessed among 102 patients by performing blood urea, serum creatinine, and Serum electrolytes after 72 hrs of birth. CBC \& X-ray chest was done to exclude sepsis. USG of KUB was done to exclude congenital anomaly. By Schwartz formula ${ }^{10} \mathrm{i}, \mathrm{e}$ $(\mathrm{eCCl}=\mathrm{Ht}(\mathrm{cm}) \times .37 /$ S.creatinine $)$ eCCL was calculated, and based on pRIFLE criteria, impaired renal function were further classified as stage I (risk) stage II (injury), stage III (failure). Neonate with AKI, renal function parameters were monitored on every alternate day.

Data were analyzed by SPSS version 12 . Results on continuous measurements are presented on Mean \pm SD (Min-Max) and categorical measurements are presented in number $(\%)$. Chi-squre has been used to find the significance on categorical scale between two variables. Pearson correlation coefficient test was done to find out correlation between renal functional status (according to eCCL) \& Apgar score.

\section{Results:}

Out of 102 cases, $48 \%$ of the cases had moderate asphyxia followed by mild (30.4\%) and severe $(21.6 \%)$ asphyxia (Fig.1). Among the study cases mean s. creatinine was $0.93 \pm 0.73 \mathrm{mg} / \mathrm{dl}$, blood urea was $75.63 \pm 47.65 \mathrm{mg} / \mathrm{dl}$, serum $\mathrm{K}+$ was $5.01 \pm 0.91 \mathrm{mmol} / \mathrm{L} \&$ serum $\mathrm{Na}+$ was $139.26 \pm 6.68 \mathrm{mmol} / \mathrm{L}$ (table-I).Acute kidney injury was noted among $68.7 \%$ of the cases according to pRIFLE criteria. In risk group average eCCL was $26.92 \pm 2.13 \mathrm{ml} /$ $\mathrm{min} / 1.73 \mathrm{~m}^{2}$ following injury $\&$ in failure group it was $13.90 \pm 2.4 \mathrm{ml} / \mathrm{min} / 1.73 \mathrm{~m}^{2} \& 8.14 \pm 1.32 \mathrm{ml} / \mathrm{min} / 1.73 \mathrm{~m}^{2}$ respectively (Table-II). Majority $18(58.06 \%)$ of the patient in the mild asphyxiated group had normal renal function. However, 9 (29.03\%) \& 4 (12.90\%) of them had stage I \& stage II renal dysfunction respectively. In Moderately asphyxiated group 13 (26.53\%) had normal renal function \& the remaining $16(32.65 \%), 17(34.69 \%)$,

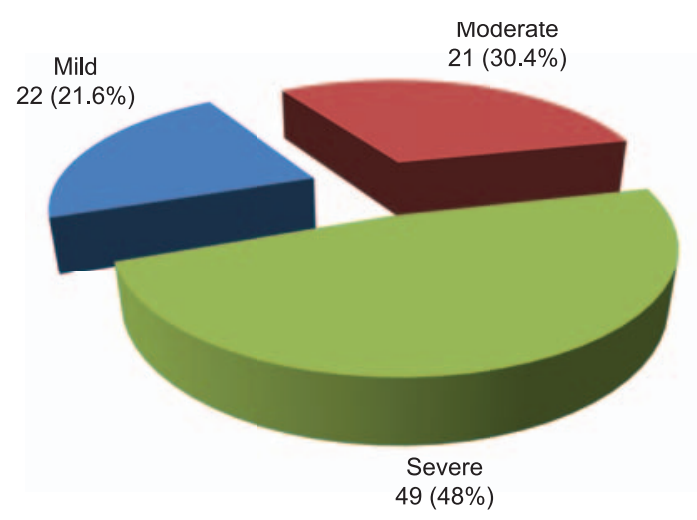

Fig.-1: Severity of asphyxia according to Apgar score at 5 min of the study Population $(n=102)$. 
$3(6.1 \%)$ had stage I, II, III renal injury. On the other hand, all the cases in severely asphyxiated group had impaired renal function ranging from Stage I $6(27.27 \%)$, stage II $6(27.27 \%)$ \& stage III $3(40.90 \%)$. This association is statistically significant, $p 0.001$ (Figure 2). eCCL was found positively correlated with Apgar score. ' $r$ ' $=0.6, p<0.002$ (Figure 3). This correlation was statistically significant.

\section{Table-I}

\begin{tabular}{lc}
\multicolumn{2}{c}{\begin{tabular}{c} 
Mean blood urea, serum creatinine, $\mathrm{K}^{+}$and $\mathrm{Na}^{+}$ \\
\multicolumn{1}{c}{ among the study population $(n=102)$}
\end{tabular}} \\
Variable & Mean $\pm \mathrm{SD}$ \\
\hline $\mathrm{S}$. Creatinine $(\mathrm{mg} / \mathrm{dl})$ & $0.93 \pm 0.73$ \\
$\mathrm{Urea}(\mathrm{mg} / \mathrm{dl})$ & $75.63 \pm 47.65$ \\
$\mathrm{~K}^{+}(\mathrm{mmol} / \mathrm{L})$ & $5.01 \pm 0.92$ \\
$\mathrm{Na}^{+}(\mathrm{mmol} / \mathrm{L})$ & $139.26 \pm 6.68$ \\
\hline
\end{tabular}

\section{Table-II}

\begin{tabular}{|c|c|c|}
\hline \multicolumn{3}{|c|}{$\begin{array}{l}\text { Renal functional status based on eCCL of the } \\
\text { study patients }(n=102)\end{array}$} \\
\hline $\begin{array}{l}\mathrm{eCCL}\left(\mathrm{ml} / \mathrm{min} / 1.73 \mathrm{~m}^{2}\right) \\
\mathrm{Mean} \pm \mathrm{SD}\end{array}$ & $\begin{array}{l}\text { Renal functional } \\
\text { status based } \\
\text { on eCCL }\end{array}$ & Frequency \\
\hline $36.40 \pm 5.1(29.9-46)$ & Normal & 32 \\
\hline $26.92 \pm 2.13(19-29.24$ & & 31 \\
\hline $13.90 \pm 2.4(10.01-17.43)$ & Injury & 27 \\
\hline $8.14 \pm 1.32(6.10-9.43)$ & Failure & 12 \\
\hline
\end{tabular}

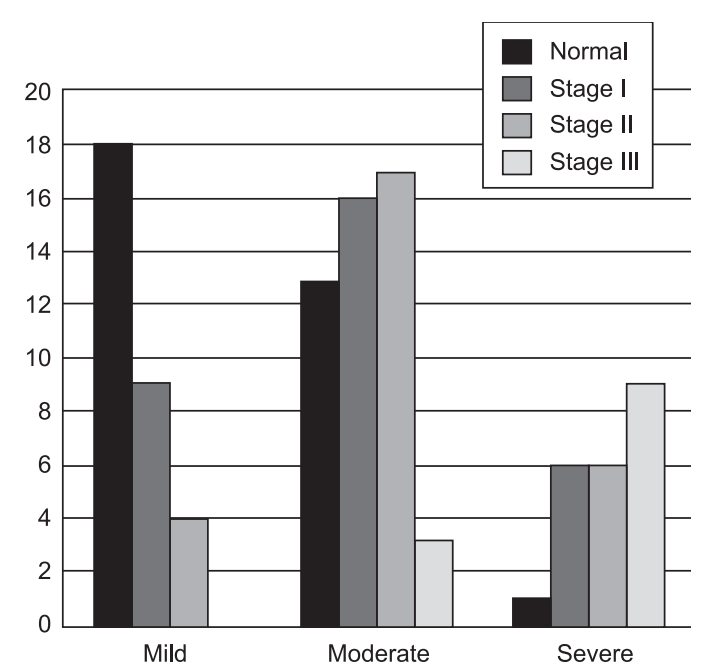

Fig.-2: Association between Renal functional status as per pRIFLE criteria (eCCL criteria) and severity of asphyxia based on APGAR score ( $n=102)$, P value: 0.001

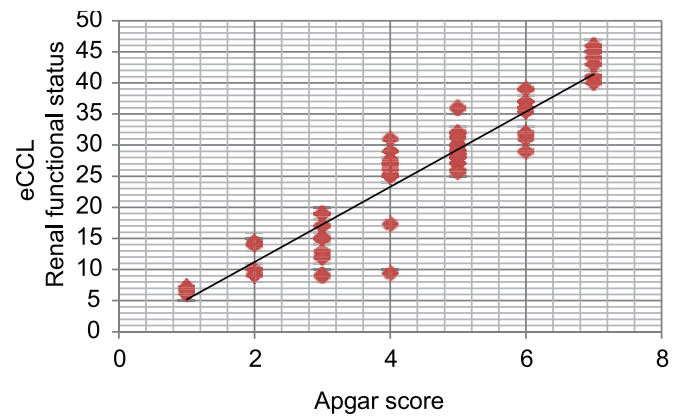

Fig.-3: Correlation between eCCL(functional status of kidney) and APGAR score among the patient $(n=102)$

\section{Discussion:}

Regarding distribution of asphyxiated babies in term of Apgar scoring, majority of them were in moderate Apgar score group (48\%) and less in severe group (21.6\%). Similarity was found in previous studies, done by Gupta et $\mathrm{al}^{3}$ and Zulfiquar et all. This similarity may reflect same geographical factor, common health problems and common health services sustained in the subcontinent.

In PNA, there is redistribution of blood flow towards brain, heart and adrenal, compromising circulation of kidney, liver, GIT and $\operatorname{skin}^{11,12}$. Hypoperfusion with concomitant hypercapnia and acidosis contribute to organ damage ${ }^{11,13}$. The kidneys of neonates are particularly vulnerable to hypoperfusion because of their physiologic characteristics like high renal vascular resistance, high plasma rennin activity, low glomerular filtration rate, decreased intracortical perfusion and decreased reabsorption of sodium in the proximal tubules causes raised urea and creatinine level ${ }^{14}$.

In the present study we found that means S. creatinine was $0.93 \pm 0.73 \mathrm{mg} / \mathrm{dl}$, blood urea was $75.63 \pm 47.65 \mathrm{mg} /$ $\mathrm{dl}$ (Table-I), which increased with the severity of kidney injury. According to pRIFLE criteria in risk group average eCCL was $26.92 \pm 2.13 \mathrm{ml} / \mathrm{min} / 1.73 \mathrm{~m}^{2}$ following injury \& in failure group it was $13.90 \pm 2.4$ $\mathrm{ml} / \mathrm{min} / 1.73 \mathrm{~m}^{2}$ \& $8.14 \pm 1.32 \mathrm{ml} / \mathrm{min} / 1.73 \mathrm{~m}^{2}$ respectively (Table-II). The percentages of ARF are varies in different studies. In most of the studies the percentage was $>40 \%$ while in present study it was $11.8 \%$ (Table-II).

Gupta et $\mathrm{al}^{3}$ in his study showed that the frequency of ARF in asphyxiated neonate was $47.14 \%$. Zulfiquar et $\mathrm{al}^{1}$ had found ARF in $46 \%$ of low Apgar scored asphyxiated baby. Aggarwal et al ${ }^{15}$ showed that ARF 
was $56 \%$. Pammi V Mohan ${ }^{16}$ showed that the incidence of ARF were $72 \%$. Sarafidis et al ${ }^{17}$ in his study showed that 8 cases with AKI among 35 neonates. Present study defined acute renal failure by pRIFLE criteria as stage 3 of acute kidney injury. In this study percentage of renal failure was $11.8 \%$ (Table-II) which is far less than other studies. This mismatch is possibly due to difference of adopted criteria for defining renal failure. In this study total number of patient with renal impairment was $68.7 \%$, Stage $1(30.39 \%)$, stage $2(26.47 \%) \&$ in stage $3(11.8 \%)$. In previous studies there was no such type of categorization and all were considered as renal failure, hence percentage of renal failure was more in previous study.

Mild ischemia results in transient loss of renal concentrating capacity, owing to the extreme sensitivity of the medullary thick ascending limb to tissue hypoxia ${ }^{18}$. More prolonged injury produces wide spread tubular dysfunction, with significant impairment in sodium and water reabsorption and decreases in GFR.

Lubis et $\mathrm{a}^{18}$ showed in their study that more number of babies with severe asphyxia suffered renal dysfunction .While present study showed $40.90 \%$ babies of severe asphyxia group suffered stage III renal dysfunction (Figure 2) \& had positive correlation between impaired renal functional status \& low Apgar scores. So the result is quite similar. The significance of the similarity is more important here as estimated renal clearance was taken as the tool for defining renal failure in both the study. The only difference was that renal dysfunction was categorized in the present study by pRIFLE criteria.

Different studies correlated renal functional status using pRIFLE criteria with renal biomarker (uCysC and uIL18) ${ }^{19,20}$. As this biomarker are not widely available and costly, this study correlated renal impairment using pRIFLE criteria with Apgar score in asphyxiated neonate, so that renal impairment can be predicted early by low Apgar score in perinatal asphyxia.

\section{Conclusion:}

Variable renal functional impairment of asphyxiated newborns can be co-related with Apgar score and the severity is directly proportional to the lower Apgar scoe.

Recommendation: All neonates with birth asphyxia admitted in neonatal intensive care units should be screened for acute kidney injury by pRIFLE criteria.
Multicentre study with large sample is also recommended.

\section{Acknowledgement:}

We are thankful to all parents of the enrolled neonates, doctors, nurses \& supporting staff of Department of Neonatology \& obstetrics of Dhaka Medical College Hospital.

Funding :Nil.

Competing interests: None stated.

\section{References:}

1. Zulfiquar M, Bouk G, Junejo B, junejo A, Shaikh S, Jamro S. Birth asphyxia relationship between hypoxic ischaemic encephalopathy grading and development of acute renal failure in term neonate. Medical channel 2009; 15:148-52.

2. Perlman JM, Tack ED, Martin T, Shackelford G, Amon E. Acute systemic organ injury in term infants after asphyxia. Am J Dis Child 1989; 143: 617-20.

3. G Gupta BD, Shanna P, Bagla J, Parakh M, Soni JP. Renal failure in asphyxiated neonates. Indian Paediatr, 2005; 42: 928- 34.

4. Rertel H, Scopes J.Rates of creatinine in babies less than one weeks of age. Arch Dis Child, 1973; 48: 717-20.

5. Kibriya F, Nilgun C, Didem A, Hulusi K, Fatma Nur S. Urinary N-acetyl- ${ }^{2}$-D Glucosaminidase Activity in Newborns As A Marker of Hypoxic-Ischemic Tubular Damage. The New Journal of Medicine, 2008; 25: 31-35.

6. R. Bellomo, C. Ronco, J. A. Kellum, R.L.Mehta, andP. Palevsky. Acute renal failure- definition, outcome measures, animal models, fluid therapy and information technology needs: the second international consensus conference of the acute dialysis quality initiative (ADQI) group. Critical Care, 2004; 8:204-12.

7. A. Akcan-Arikan, M. Zappitelli, L. L. Loftis, K. K. Washburn, L. S. Jefferson, and S. L. Goldstein. Modified RIFLE criteria in critically ill children with acute kidney injury. Kidney International, 2007; 71: 1028-35.

8. Sreedharan R, Avner ED. Acute reanl failure In: Behrman RE, Kliegman RM, Jenson WG,Stanton BF, Schor NF eds. Nelson text book of pediatrics. 19th ed Philadelphia: WB Saunders company, 2011: 1818—22.

9. Gomella TL, Cunningham MD, Eyal FG. Neonatology, management, procedures, on call problems, diseases and drugs. $7^{\text {th }}$ ed Lange: McGraw-Hill companies, 2013:805-14.

10. Schwartz GJ, Munoz A, Michael F, Schneider MF et al. New equations to estimate GFR in children with CKD. J Am Soc Nephrol, 2009; 20: 629-37.

11. Stoll BJ, Kliegman RM. Nervous system disorders: Hypoxiaischemia. In: Behrman RE, Kliegman RM, Jenson HB, eds. 
Nelson text book of pediatrics. 17th ed Philadelphia: WB Saunders company, 2004: 556-67.

12. Bhutta ZA. Mechanisms of perinatal hypoxic ischemic encephalopathy: Current concepts. Specialist. 1992; 8: 2737.

13. Covey MV, Levison SW. Pathophysiology of perinatal hypoxia- ischemia and the prospects for repair from endogenous and exogenous stem cells. Neo Reviews, 2006; 7: $353-70$.

14. Mathur NB, Agarwal HS, Maria A. Acute renal failure in neonatal sepsis. Indian J Pediatr, 2006; 73:499-502

15. Aggarwal A, Kumar P, Chowdary G, Majumder S, Narag A. Evaluation of renal functions in asphyxiated neonates. J Tropical pediatrics, 2005; 51: 295-9.
16. Mohan PV, Pai PM .Renal insult in Asphyxia Neonatorum . Indian j Pediatr, 2000; 37: 1102-06.

17. K. Sarafidis, E. Tsepkentzi, E. Agakidou et al. Serum and urine acute kidney injury biomarkers in asphyxiated neonates. Pediatric Nephrology, 2012; 27: 1575-82.

18. Ellya Nova Lubis, Srie Yanda, Khainir Akbar, Guslihan Dasa Tjipta, Dachrul Aldy. The effect of neonatal asphyxia on renal function. Paediatr Indones, 2001; 41:175-79.

19. Y. Li, C. Fu, X. Zhou et al. Urine interleukin-18 and cystatin$\mathrm{C}$ as biomarkers of acute kidney injury in critically ill neonates. Pediatric Nephrology, 2012; 27: 851-60.

20. A. T. Elmas, Y. Tabel, and O. N. Elmas. Serum cystatin C predicts acute kidney injury in preterm neonates with respiratory distress syndrome. Pediatric Nephrology, 2013; 28: $477-84$. 